\title{
Smart optical probes for near-infrared fluorescence imaging of Alzheimer's disease pathology
}

\author{
Scott B. Raymond • Jesse Skoch • Ivory D. Hills • \\ Evgueni E. Nesterov • Timothy M. Swager • \\ Brian J. Bacskai
}

Published online: 20 March 2008

(C) Springer-Verlag 2008

Eur J Nucl Med Mol Imaging (2008) 35 (Suppl 1) 35: 593-598

Some of the references were misnumbered in the text, as follows:

Results, $A \beta$-dependent spectra, "The recent development of liquid crystal ... [24]" should be [25].

Conclusions, "For in vivo efficacy, brain molecular ... [26]" should be [27].

Conclusions, "Our group has developed a theoretical ... [14]" should be [15].

Conclusions, "We and others have demonstrated ... [13, 24]" should be [14, 24].

Conclusions, "Likewise, spectral imaging has seen ... $[15,25]$ " should be [25].

The authors apologize for this mistake and any confusion it may have caused.

The online version of the original article can be found at http://dx.doi. org/10.1007/s00259-007-0708-7.

S. B. Raymond · B. J. Bacskai $(\bowtie)$

Alzheimer's Disease Research Unit, Department of Neurology,

Massachusetts General Hospital,

114 16th St,

Charlestown, MA 02129, USA

e-mail: bbacskai@partners.org

J. Skoch

Department of Pharmacology, University of Colorado at Denver and Health Sciences Center,

Denver, CO 80262, USA

E. E. Nesterov

Department of Chemistry, Louisiana State University,

Baton Rouge, LA 70803, USA

I. D. Hills · T. M. Swager

Department of Chemistry and Institute for Soldier

Nanotechnologies, Massachusetts Institute of Technology,

Cambridge, MA 02139, USA 